\title{
Effect of Zircon on the Properties of Magnesia-based Castable
}

\author{
Haixia Feng ${ }^{1, a}$, Jun Liü ${ }^{2, b}$ \\ ${ }^{1,2}$ Sinosteel Luoyang Institute of Refractories Research Co., Ltd., Luoyang 471039, China \\ ${ }^{1,2}$ State Key Laboratory of Advanced Refractories, Luoyang 471039, China \\ afenghx2010@126.com, 'bliuj@lirrc.com
}

Keywords: zircon, magnesia-based castable, molten slag, basicity, mechanism analysis.

\begin{abstract}
This paper intended to improve the comprehensive performance of the material by introducing zircon powder in magnesia-based castable. It was found that forsterite generated at the medium temperature, resulting that apparent porosity of the samples increased, bulk density decreased and cold crushing sthength increased. Adding zircon samples showed good performance of slag corrosion resistance and slag penetration resistance for high basicity slag of 3.45; but not well for low basicity slag of 0.92 . At the same time, the high basicity slag resistance mechanism analysis of magnesia-based castable was explored further.
\end{abstract}

\section{Introduction}

Magnesia-based refractory castable has good penetration resistance to metal and alkaline slag, but the performance of slag corrosion resistance and thermal shock resistance is very poor. Because of magnesium oxide's big thermal expansion coefficient $\left(\alpha=14 \sim 15 \times 10^{-6}\right)$, the material has large thermal expansion to form thermal stress, poor sinterability and low cold crushing strength under medium temperature condition; but greater thermal stress causes thermal spalling at high temperature. According to the results of researchers in our industry ${ }^{[1,2,3]}$, it was generally believed that adding zircon should help to improve the slag resistance and thermal shock resistance. In this work, zircon powder was added in M-S-H bonded maganesia-based castable, trying to improve the performance at medium and high temperature. The static slag-resistance tests of two different basicity slags were researched, and mechanism analysis of the material's molten slag resistance adding zircon powder was explored.

\section{Experiment}

The raw material of experiment included fused magnesite, silicon powder and zircon powder, the chemical composition of main materials is listed in Table 1.The proportion of the aggregate and matrix was $70: 30$. Samples of $40 \mathrm{~mm} \times 40 \mathrm{~mm} \times 160 \mathrm{~mm}$ were made by casting and tested according to the Chinese Standard. Static slag-resistance tests were done (slag-resistance crucible is shown in Figure 1) using different basictiy slags of 0.92 and 3.45. Table 2 shows the composition of molten slags.

Table 1 Chemical composition of main raw materials [wt\%]

\begin{tabular}{rcccccc}
\hline Raw materials & $\mathrm{MgO}$ & $\mathrm{CaO}$ & $\mathrm{SiO}_{2}$ & $\mathrm{Fe}_{2} \mathrm{O}_{3}$ & $\mathrm{Al}_{2} \mathrm{O}_{3}$ & $\mathrm{ZrO}_{2}$ \\
\hline Fused magnesite & 96.28 & 1.34 & 1.02 & 0.46 & 0.12 & $/$ \\
Silicon powder & 0.21 & $/$ & 94.57 & 0.06 & 0.18 & $/$ \\
Zircon powder & $/$ & $/$ & 32.02 & 0.03 & 0.41 & 67.14 \\
\hline
\end{tabular}


Table 2 Chemical composition of two different molten slags [wt\%]

\begin{tabular}{cccccccc}
\hline Molten slag & $\mathrm{CaO}$ & $\mathrm{SiO}_{2}$ & $\mathrm{Al}_{2} \mathrm{O}_{3}$ & $\mathrm{MgO}$ & $\mathrm{Fe}_{2} \mathrm{O}_{3}$ & $\mathrm{MnO}_{2}$ & $\mathrm{R}$ \\
\hline Low basicity slag & 26.3 & 28.7 & 29.3 & 8.5 & 4.2 & 0.6 & 0.92 \\
High basicity slag & 37.3 & 10.8 & 30.6 & 8.6 & 8.4 & 2.8 & 3.45 \\
\hline
\end{tabular}

Remark: R represents basicity of molten slag.

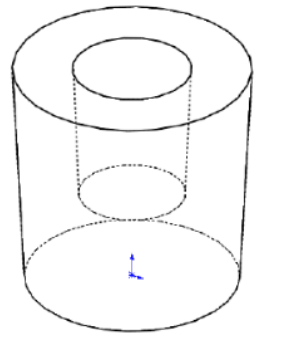

1-a Overall shape

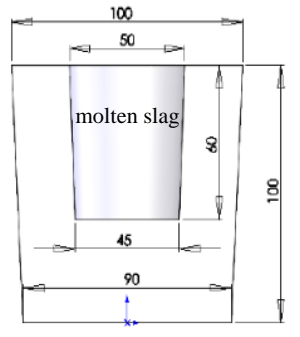

1-b Cross section view

Fig. 1 Slag-resistance crucible picture

\section{Results and discussion}

Conventional performance evaluation. The performance indexes of magnesia-based castable samples adding zircon are shown in Table 3. It can be seen that the properties of the samples have been changed after heat treatment at medium temperature, bulk density of the samples decreases, apparent porosity, permanent linear change and cold crushing strength increase. At this time magnesia in the matrix and amorphous silicon decomposed from zircon were easy to interact to generate forsterite phase $\left(\mathrm{M}_{2} \mathrm{~S}\right)$ and free $\mathrm{ZrO}_{2}$, this process was a volume expansion reaction, which leaded to above the results. Small particle size of $\mathrm{M}_{2} \mathrm{~S}$ helped to strengthen the structure of the matrix, forming a more reasonable micro-pore size distribution structure ${ }^{[2]}$. After high temperature treatment, samples showed a linear shrinkage (P.L.C=-0.42\%), but the strength decreased. The reasons might have three aspects: (1) In the M-S-H system, silica, together with the impurities, and other raw materials formed low melting phase at high temperature to cause shrinkage of samples, moreover part zircon powder have been sintered which could also lead to above results. (2) The activity of zirconia which came from dissociation reaction of zircon was so high that phase transformation occurred easily when temperature decreased gradually, resulting that the structure of sample became loose and strength decreased. (3) The self-sintering ability of magnesia-based material under high temperature is relatively poor because magnesia has large thermal expansion coefficient, hence magnesia-based castable has a relatively low strength.

Table 3 Conventional performance of magnesia-based castable

\begin{tabular}{cccccc}
\hline $\begin{array}{c}\text { Temperature } \\
{\left[{ }^{\circ} \mathrm{C}\right]}\end{array}$ & $\begin{array}{c}\text { P.L.C } \\
{[\%]}\end{array}$ & $\begin{array}{c}\text { B.D. } \\
{\left[\mathrm{g} / \mathrm{cm}^{3}\right]}\end{array}$ & $\begin{array}{c}\text { A.P. } \\
{[\%]}\end{array}$ & $\begin{array}{c}\text { CMOR } \\
{[\mathrm{MPa}]}\end{array}$ & $\begin{array}{c}\text { CCS } \\
{[\mathrm{MPa}]}\end{array}$ \\
\hline $110^{\circ} \mathrm{C}$ & $/$ & 3.04 & 11.5 & 6.1 & 53.4 \\
$1000^{\circ} \mathrm{C}$ & +0.24 & 2.99 & 15.7 & 2.1 & 54.0 \\
$1550^{\circ} \mathrm{C}$ & -0.42 & 3.05 & 13.4 & 6.7 & 37.3 \\
\hline
\end{tabular}

Comparison of slag resistance tests. Table 4 shows different schemes of slag-resistance crucibles. Mark of "Blank" represents pure magnesia-based castable without adding zircon, and mark of "Zircon" represents refractory castable adding zircon. The slag-resistance results are seen in 
Figure 2, using different basicity slags of 0.92 and 3.45 respectively. Crucible of mark "2-A" (without adding zircon) appears obvious cracks, which indicates that the material is easily damaged against low basicity molten slag. Crucible 2-B adding zircon powder has no clear cracks on the surface of crucible samples. $\mathrm{ZrO}_{2}$ introduced by zircon could form phase transformation toughening and helped to greatly improve thermal shock resistance of the material. Magnesia-based material itself has good penetration resistance to alkali slag, so sample crucible of A and B have a lower degree of slag erosion, and the difference of two samples is very small (see Fig.2-A and Fig.2-B). However, $\mathrm{SiO}_{2}$ was introduced into samples after adding zircon, the improvement of $\mathrm{SiO}_{2}$ content could generate more liquid phase, thus added to the severe penetration of molten slag to the material. And low basicity slag had a lower melting point of only about $1260{ }^{\circ} \mathrm{C}$ to penetrate into the specimen more easily, so that crucible 2-B sample exhibited more significant local penetration (see Fig. 2-B).

High basicity molten slag not only had a much higher $\mathrm{CaO}-$ to-SiO${ }_{2}$ ratio, but also a higher melting point of about $1350{ }^{\circ} \mathrm{C}$. When smelting condition was in higher temperature, molten slag had a bigger viscosity and a worse dispersion; while temperature decreased, this kind of molten slag easily gathered together (see Fig. 2-C). Free $\mathrm{ZrO}_{2}$ from zircon dissociation had so high activity that it was easy to react with $\mathrm{CaO}$ of slag to form high melting point mineral phase calcium zirconate; intergranular $\mathrm{Fe}_{2} \mathrm{O}_{3}$ and $\mathrm{MnO}$ dissolved into periclase were soluble in magnesium oxide to form precipitation phase magnesium ferrite, then periclase grain growed further ${ }^{[3]}$. Above two cases could block channels of slag penetration to improve slag resistance. At the same time, zirconia fused into slag further increased the viscosity of molten slag, slowed the rate of the slag penetration, and then improved slag resistance of the material ${ }^{[4,5]}$. Overall structure was interweaved to form network shape when cooled (see Fig. 2-D), which also proved the above analysis.

Through above results it indicated that adding zircon was more suitable for smelting slag of high basicity, and the amount of zircon should be controlled in a certain range.

Table 4 Different series of crucible tests

\begin{tabular}{ccccc}
\hline Mark of crucible & 2-A & 2-B & 2-C & 2-D \\
\hline Material & Blank & Adding zircon & Blank & Adding zircon \\
Molten slag & Low basicity & Low basicity & How basicity & How basicity \\
\hline
\end{tabular}

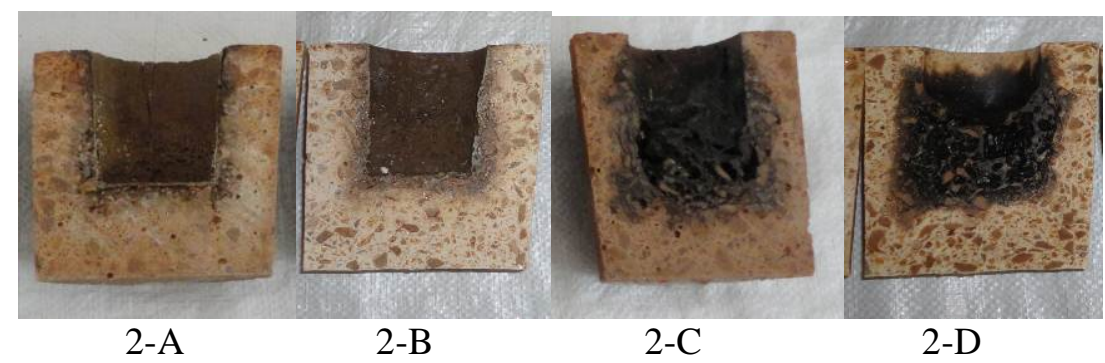

Fig. 2 The profile schematic diagram of slag crucible

\section{Conclusions}

(1) The formation of the forsterite in magnesia-based castable at medium temperature strengthened the matrix microstructure, material's strength increased.

(2) Slag resistance test results showed that: for low basicity slag of 0.92 samples adding zircon had poor slag penetration resistance for high basicity slag of 3.45, samples showed good slag resistances to penetration and corrosion.

(3) Adding zircon was more suitable for the working conditions of smelting high basicity slag. 
(4) With different slag composition, smelting temperature, smelting time and zircon's chemical component, the optimum addition amount of zircon could be different. It needed to be further explored according to different situation.

\section{References}

[1] Z.G. Li, F.B. Ye, X.C. Zhong, Influences of zircon and alumina addition on the properties of MgO-based castables [J]. Naihuo Cailiao (Refractories, in Chinese). 2001, 35(6)320-322.

[2] Y.S. Li, N. Li, Effect of zircon micropowder on properties of magnesia castable[J]. Naihuo Cailiao (Refractories, in Chinese). 1998, 32(5)254-256,259.

[3] J.C. Wei, J.B. Tu, The effect of zircon on slag resistance and thermal shock resistant of magnesia castable[J]. Journal of Hebei Institute of Technology. 2004, 26(4)58-61,65.

[4] S.L. Chen, J.L. Sun, X.Y. Xiong, et al., Corrosion resistance mechanisms of magnesia-zircite brick against non-oriented and oriented electric steel slag in RH[J]. Steelmaking. 2008, 24(6)53-56.

[5] R.R. Chen, P.X. He, J.N. Mou, et al., Research of slag corrosion resistance of chrome free refractories for RH vessel lining[J]. Naihuo Cailiao (Refractories, in Chinese). 2005, 39(5)357-360. 